\title{
Monetary versus Fiscal Policy Effects: A Review of the Debate
}

\author{
Bennett T. McCallum \\ CARNEGIE-MELLON UNIVERSITY \\ AND NATIONAL BUREAU OF ECONOMIC RESEARCH
}

\section{Introduction}

The "monetary versus fiscal policy" debate has not attracted much attention in recent years, and, in some ways, this is not to be regretted. It may therefore be useful to begin this discussion with a quote from Phillip Cagan $(1978,85-86)$ :

\begin{abstract}
No one who was not in touch with the economics profession in the 1940s and 1950s can quite imagine the state of thinking then in the profession at large on monetary theory and policy. The quantity of money was not considered important, indeed was hardly worth mentioning, for questions of aggregate demand, unemployment, and even inflation... Textbooks in basic economics and even in money and banking mentioned the quantity theory of money, if at all, only to hold it up to ridicule. Those textbooks produced an entire cohort of professional economists who became the teachers of hordes of economics students. There were, of course, many exceptions, most notably at the University of Chicago ... But if you traveled among the profession at large, mention of the quantity of money elicited puzzled glances of disbelief or sly smiles of condescension.
\end{abstract}

As a former member of the horde of students that Cagan refers to, I would modify his statement only by suggesting that the period in question lasted longer than he indicates. For readers who find this claim hard to

The author is indebted to Carl Christ, Stanley Fischer, Robert King, Thomas Mayer, Lawrence Meyer, and Allan Meltzer for helpful comments and to the National Science Foundation (SES 84-08691) for financial assistance. 
believe, I would suggest perusal of the contents of the American Economic Association's Readings in Business Cycles, published in 1965 (Gordon and Klein 1965). Another interesting record is provided by the chapter on inflation in Ackley (1961), the standard, graduate macro text of the 1960s. Ackley begins with a brief description of the "classical school" theory in which inflation depends primarily upon growth of the quantity of money, but quickly moves on to other ideas. ${ }^{1}$

Today, of course, matters are different. There are few economists who would label themselves "monetarists," but most publishing macroeconomists hold views that would have been two standard deviations away from the mean-in the monetarist direction-in 1965. As one piece of evidence in support of that claim, I would point to the specifications (i.e., list of variables) of vector autoregression (VAR) models currently being used for forecasting and/or analysis. In particular, the VAR systems of Sims (1980, 1982), Litterman (1982), Gordon and King (1982), Webb (1984), and B. M. Friedman (1984) all include monetary aggregates but no fiscal variables.

Both sides in the debate can of course claim victory: the monetary policy supporters for the reasons implicit in the foregoing comparison, and the fiscal policy supporters by citing theory and evidence indicating that fiscal actions are not without effect on aggregate demand. But the shift has certainly been in favor of the former.

The purpose of this paper is to review developments bearing on this debate over the last 20 years. To describe all of the significant items in the literature would require a paper of inordinate length and one that would be extremely dull for the participants at this conference, most of whom are intimately familiar with much of the material. Fortunately, it turns out to be unnecessary for me to provide an extensive treatment of the main threads of the argument, for a careful review was published fairly recently by Meyer and Rasche (1980). I will be able, then, to pass quickly through the well-known items and arguments and focus my attention on items that (i) have been neglected, (ii) are fairly recent, or (iii) are somewhat original. The organization of the paper is very simple: Section 2 is concerned with empirical studies and econometric points of interpretation, Section 3 discusses some of the main theoretical issues, and Section 4 provides some tentative conclusions and judgments.

\section{Empirical Results and Econometric Issues}

\subsection{Single-equation results}

In discussing the empirical analysis and related issues, it is convenient to organize the discussion around results featured in a long series of articles prepared by the research department of the Federal Reserve Bank of St. 
Louis. ${ }^{2}$ Brief mention should be made, however, of the earlier paper by Friedman and Meiselman (1963), which is not discussed by Meyer and Rasche.

The central ingredient of the Friedman-Meiselman study was a comparison of simple correlations (based on annual U.S. data for 1897-1958 and subperiods) of consumption with money stock magnitudes, on the one hand, and consumption with "autonomous" fiscal variables, ${ }^{3}$ on the other hand. Friedman and Meiselman found that movements in consumption were more highly correlated with monetary rather than fiscal variations. Their own summary statement goes as follows:

The results are strikingly one-sided. Except for the early years of the Great Depression, money ... is more closely related to consumption than is autonomous expenditures .... This is so both for nominal values... and for "real" values ... . It is true both for absolute values and for year-to-year or quarter-to-quarter changes. Such correlation as there is between autonomous expenditures and consumption is in the main a disguised reflection of the common effect of money on both .... One implication of the results is that the critical variable for monetary policy is the stock of money, not interest rates or investment expenditures. $(1963,166)$

Given the climate described by Cagan, the central role of the consumption function in Keynesian analysis, and some questionable methodology, the Friedman-Meiselman study was welcomed by the profession about like an unexpected slap in the face. Strongly critical studies were published by Hester (1964), Ando and Modigliani (1965), and DePrano and Mayer (1965). Strongly worded replies and rejoinders of great length followed promptly.

It is clear that the Friedman-Meiselman approach was in fact open to several methodological objections. Its critics emphasized the questionable nature of the measure used for autonomous expenditures as well as the delineation of sample subperiods. Especially troublesome was the focus on contemporaneous relationships in single regression equations including only one or two explanatory variables. Most researchers in macroeconomics believed, I would guess, that investigation of the issues under discussion could be adequately carried out in the context of a fully specified, simultaneous-equation, econometric model. The judgment of Blinder and Solow $(1974,65)$, expressed a few years later, was that "all of this was essentially pointless. The issue is simply not to be settled by comparing goodness of fit of one-equation models that are far too primitive to represent any theory adequately."

Thus the Friedman-Meiselman results were in the process of being shrugged off when the first of the St. Louis studies-that of Andersen and Jordan (1968)-appeared. As is very well known, that study featured a least squares regression fit to quarterly U.S. data for 1952.1-1968.2 in 
which the dependent variable was the change in nominal GNP, and the explanatory variables were current and lagged values of changes in the money stock (M1 or base), full-employment expenditures, and fullemployment tax receipts. The striking finding was that the sum of the coefficients on the monetary variable was highly significant, whereas the sum of the coefficients on both fiscal variables was insignificantly different from zero. ${ }^{4}$

\subsection{Econometric objections}

Again, sharply critical objections were raised. The main lines of argument were brought together by Blinder and Solow (1974) and nicely reviewed by Meyer and Rasche (1980). My strategy here will be to focus on three points emphasized by Blinder and Solow (see below) and on the evidence concerning reliability of "reduced-form" procedures that was subsequently described by Modigliani and Ando (1976). It will be convenient, though, to begin by quickly mentioning the observation of Benjamin Friedman (1977) that when data for the period 1970.1-1976.2 is added to the Andersen-Carlson (1970) sample, the sum of the fiscal variable coefficients becomes significantly positive. It was quickly shown by Carlson (1978), however, that this conclusion does not obtain when the variables are entered in rate-of-change form rather than as first differences. In effect, Carlson's suggested specification amount to

$$
\Delta y_{t}=\alpha+\beta(L) \Delta m_{t}+\gamma(L) \Delta g_{t}+u_{t},
$$

where $y_{t}, m_{t}$, and $g_{t}$ are logarithms of nominal GNP, a money stock measure, and a fiscal variable, respectively; $u_{t}$ is a stochastic disturbance, and $\beta(L)$ and $\gamma(L)$ denote finite polynomials in the lag operator defined by $L^{n} x_{t}=x_{t-n}$, so that $\beta(L) \Delta m_{t}$ stands for a distributed lag such as $\beta_{0} \Delta m_{t}$ $+\beta_{1} \Delta m_{t-1}+\cdots+\beta_{k} \Delta m_{t-k}$. Carlson's specification not only has the desirable feature of relating relative rather than absolute changes, but it also leads to residuals that are more consistent with the standard assumption that $u_{t}$ is a white-noise disturbance. ${ }^{5}$ Consequently, (1) seems preferable to the specification used previously, and this judgment leads to the conclusion that the inclusion of data for years since 1969 does not reverse the original finding that the sum of the $\gamma_{j}$ coefficients is insignificantly different from zero. In what follows I will accordingly presume that (1) is the relevant specification.

Let us now consider, then, the criticisms of Blinder and Solow (1974). Those writers summarize their position very concisely as follows:

In summary, the Andersen-Jordan study errs for at least three reasons, any one of which is sufficient to render their results meaningless. First, by omit- 
ting all exogenous variables other than fiscal or monetary policy, they seriously misspecify the reduced-form equation for real [sic] output .... Second, they use an incorrect measure of fiscal policy, which biases the coefficient toward zero. Finally, and most damaging to their position, they treat fiscal and monetary policies as exogenous when it is intuitively obvious that the authorities are in some sense reacting to movements in the macroeconomy. (pp. 70-71)

These three difficulties correspond to those discussed by Meyer and Rasche (1980, 56-63) and Batten and Thornton (1983, n. 2). We will take them in turn, starting with the omission of exogenous variables. In this case the contention is that the true specification is not (1) but

$$
\Delta y_{t}=\alpha+\beta(L) \Delta m_{t}+\gamma(L) \Delta g_{t}+\delta(L) \Delta z_{t}+u_{t},
$$

where $z_{t}$ is an additional variable ${ }^{6}$ that has an important influence on $y_{t}$. For the moment, let us suppose that $\Delta m_{t}$ and $\Delta g_{t}$ are in fact exogenous, a supposition that will be considered later in connection with the third difficulty. Now Blinder and Solow refer to $z_{t}$ as an exogenous variable. But the conditions for true statistical exogeneity are extremely stringent: $z_{t}$ must be generated by a process that is independent of current and past values of $y_{t}$ (and thus $u_{t}$ ). But it is hard to imagine any important macroeconomic variable that is truly exogenous in that sense; even population growth and technical change probably respond (with lags) to fluctuations in GNP. ${ }^{7}$ The point is better expressed, then, as suggesting that (2) is applicable with $\Delta z_{t}$ interpreted as an endogenous variable that is affected by $\Delta y_{t}, \Delta m_{t}$, and $\Delta g_{t}$ only with a lag. Suppose that relation is

$$
\Delta z_{t}=a_{0}+a_{1} \Delta y_{t-1}+a_{2} \Delta m_{t-1}+a_{3} \Delta g_{t-1}+\xi_{t},
$$

where $\xi_{t}$ is a stochastic disturbance term. Then by substitution and rearrangement we have

$$
\begin{gathered}
\Delta y_{t}=\left[\alpha+\delta(L) a_{0}\right]+\left[\beta(L)+a_{2} L \delta(L)\right] \Delta m_{t} \\
+\left[\gamma(L)+a_{3} L \delta(L)\right] \Delta g_{t}+a_{1} \delta(L) \Delta y_{t-1}+\left[u_{t}+\delta(L) \xi_{t}\right],
\end{gathered}
$$

which is not in the form of (2) because of the appearance of $a_{1} \delta(L) y_{t-1}$. That can be remedied, however, by moving the $\Delta y_{t-1}$ term to the left side and multiplying through by $\left[1-L a_{1} \delta(L)\right]^{-1}$ :

$$
\Delta y_{t}=\alpha^{\prime}+\beta^{\prime}(L) \Delta m_{t}+\gamma^{\prime}(L) \Delta g_{t}+u^{\prime}{ }_{t} .
$$

Here we have a relation of the form of (2), but (of course) with disturbances and parameters that are quite different: 


$$
\begin{aligned}
\beta^{\prime} & =\left[1-L a_{1} \delta(L)\right]^{-1}\left[\beta(L)+a_{2} L \delta(L)\right] \\
\gamma^{\prime} & =\left[1-L a_{1} \delta(L)\right]^{-1}\left[\gamma(L)+a_{3} L \delta(L)\right] \\
u^{\prime} & =\left[1-L a_{1} \delta(L)\right]^{-1}\left[u_{t}+\delta(L) \xi_{t}\right] .
\end{aligned}
$$

What we have in (5) is not a reduced-form equation but a final-form equation for $\Delta y_{t}$ (still assuming that $\Delta m_{t}$ and $\Delta g_{t}$ are truly exogenous). ${ }^{8}$

Thus we see that the coefficients in (5), which will be estimated by the St. Louis procedure, are not the reduced-form coefficients in (1). The estimated values will, under the assumption that $\delta(L) \neq 0$ in (2) and that (3) is a "stable" relationship, reflect indirect influences of $\Delta m_{t}$ and $\Delta g_{t}$ on $\Delta y_{t}$ by way of $\Delta z_{l}$. But the importance of that observation is quite unclear; the coefficients in a reduced-form equation like (1) also reflect influences that are "indirect." The first problem mentioned by Blinder and Solow hardly justifies, then, terming the St. Louis estimates "meaningless." It merely implies that in interpreting the estimates it may be necessary to keep in mind that they reflect "indirect" effects. ${ }^{9}$

It should be added that the foregoing argument presumes that Eq. (3) is "stable"-that is, unchanging over the sample period. Such relationships may in fact change significantly over real-time sample periods, for reasons explained by Lucas (1976) or for other reasons. But precisely the same must be said for (1); these two relationships are on the same footing in that respect. If there is reason to believe that (1) is stable over a period, there is no particular reason to expect (3) to be shifting.

Let us turn next to the second of the Blinder-Solow (1974) points-that the St. Louis measures of fiscal policy may be "incorrect." This means that the St. Louis variable does not correspond to the "weighted standardized surplus" shown by Blinder and Solow $(1974,23,33-34)$ to be the measure that would appear in a reduced-form expression within the particular model that they use for illustrative purposes. But this is a conclusive criticism only to one who has some attachment to the particular model in question, ${ }^{10}$ and then only if he believes that the effect of using alternative measures would be large. Although Corrigan (1970) found that a specific measure, which Blinder and Solow consider reasonably attractive, led to estimates indicating a significant fiscal effect, it is my impression that the variable measurement problem is not of overwhelming importance empirically. Or, to put it differently, if there is a fiscal policy measure that carries a strongly significant sum of coefficients in an equation of the St. Louis form, its existence has not been well publicized. ${ }^{11}$ In any event, analysis of the policy-variable measurement issue is undermined by the third problem discussed by Blinder and Solow, to which we now turn. 
The issue in this case results from the endogeneity of policy actions, a topic that was investigated in detail by Goldfeld and Blinder (1972). The Goldfeld-Blinder paper correctly emphasizes the distinction between exogeneity, in the sense of coming from outside the private sector of the economy and exogeneity in the statistical sense. And they note that it is almost inconceivable that either the monetary or the fiscal variables in the St. Louis studies could be exogenous in the latter sense, for that would imply that the authorities' actions are not systematically influenced to any significant extent by current or past macroeconomic conditions. If in fact the authorities' actions are so influenced, then (2) may not be a proper reduced-form equation even if no variables are omitted. In particular, the disturbance term $u_{t}$ will be correlated with regressor variables if policy actions respond to current-quarter conditions, or if policy responds with a lag but the disturbance in (1) is autocorrelated. Under such circumstances, least squares estimates of $\beta(L)$ and $\gamma(L)$ will of course be biased and inconsistent.

This point is clearly correct in principle and could easily be of importance empirically. ${ }^{12}$ The numbers reported in Goldfeld and Blinder's Table 8 suggest, however, that the downward bias should be about the same for monetary variable coefficients as for fiscal variable coefficients, except in the event that the fiscal authorities are extremely prompt and accurate in their stabilization efforts. It seems unlikely that this would be the case for the U.S. economy.

Nevertheless, the point is important enough to warrant continued discussion. Given that the policy authorities do respond to current or recent macroeconomic conditions, the best way to proceed in estimating equations like (1) or (5) is to append policy-rule or reaction-function specifications for the authorities and carry out simultaneous equation estimation, as recommended by Goldfeld and Blinder. But it is not necessary to explicitly formulate equations descriptive of policy behavior; consistent estimates of (5) can be obtained by estimating that equation in isolation but using instrumental variables (IV) rather than ordinary least squares (OLS) estimators. Comparisons of IV and OLS results should indicate whether severe biases are in fact induced by the reactive behavior of the policy authorities.

The results of an extremely brief and tentative exploration of that type are reported in Table 2.1. The first pair of numerical columns gives coefficient and standard error values for an OLS regression of the form of (5), using quarterly data on nominal GNP, the Ml money supply, and nominal federal purchases of goods and services for 1954-80. Despite the absence of polynomial constraints and the use of a different expenditure variable, the results are much like those that have been featured in the St. Louis studies. In particular, the $\Delta m_{t-j}$ variables are strongly significant 
Table 2.1

\begin{tabular}{|c|c|c|c|c|}
\hline \multirow[b]{3}{*}{ Regressor } & \multicolumn{3}{|c|}{$\begin{array}{l}\text { OLS vs. IV Estimates of St. Louis Equations } \\
\text { Sample Period: } 1954.1-1980.4\end{array}$} & \\
\hline & \multicolumn{2}{|c|}{ OLS Estimates } & \multicolumn{2}{|c|}{ IV Estimates ${ }^{*}$} \\
\hline & Coef. & (SE) & Coef. & (SE) \\
\hline Constant & 0.007 & $(0.002)$ & 0.009 & $(0.003)$ \\
\hline$\Delta \mathrm{m}_{\mathrm{t}}$ & 0.651 & $(0.119)$ & 0.167 & $(0.387)$ \\
\hline$\Delta \mathrm{m}_{\mathrm{t}-1}$ & 0.226 & $(0.128)$ & 0.615 & $(0.320)$ \\
\hline$\Delta \mathrm{m}_{\mathrm{t}-2}$ & 0.308 & $(0.148)$ & 0.191 & $(0.251)$ \\
\hline$\Delta \mathrm{m}_{\mathrm{t}-3}$ & 0.148 & $(0.182)$ & 0.401 & $(0.341)$ \\
\hline$\Delta \mathrm{m}_{\mathrm{t}-4}$ & -0.240 & $(0.155)$ & -0.297 & $(0.240)$ \\
\hline$\Delta g_{t}$ & 0.099 & $(0.031)$ & -0.190 & (0.221) \\
\hline$\Delta \mathfrak{g}_{\mathrm{t}-1}$ & 0.026 & $(0.032)$ & 0.058 & $(0.079)$ \\
\hline$\Delta g_{t-2}$ & 0.005 & $(0.032)$ & 0.049 & $(0.055)$ \\
\hline$\Delta g_{t-3}$ & -0.050 & $(0.032)$ & -0.025 & $(0.048)$ \\
\hline$\Delta \mathrm{g}_{\mathrm{t}-4}$ & -0.038 & $(0.031)$ & -0.033 & $(0.044)$ \\
\hline $\mathrm{R}^{2}$ & 0.531 & & & 0.053 \\
\hline DW & 1.90 & & & 1.91 \\
\hline SE & 0.0080 & & & 0.0113 \\
\hline
\end{tabular}

as a group with coefficients summing to 1.09 , whereas the fiscal variables enter less strongly and their coefficients sum to only $0.04 .^{13}$

In the second pair of numerical columns are IV estimates for the same period, with the instruments for $\Delta m_{t}$ and $\Delta g_{t}$ created by first-stage regressions of those variables on their lagged values $\Delta m_{t-1}, \Delta g_{t-1}, \ldots, \Delta m_{t-4}$, $\Delta g_{t-4}$, plus $r_{t-1}$ and $r_{t-2}$, with $r_{t}$ the 90-day treasury bill rate. Indentification is provided by the assumption that $r_{t-1}$ and $r_{t-2}$ affect policy instrument settings in period $t$. Because there is no strong sign of serially correlated disturbances, these estimates should be consistent for the parameters of (5) even in the presence of current-period responses of $\Delta m_{t}$ and $\Delta g_{t}$ to values of $\Delta y_{t}$ or other endogenous variables. As is readily apparent, there are two major differences in these estimates as compared to OLS. First, the coefficients attached to current-period values of $\Delta m_{t}$ and $\Delta g_{i}$ are much smaller, with the latter turning negative. Second, the standard errors are much larger, indicating a substantial reduction in the reported accuracy of the coefficient estimators. In part, the latter is induced by lower overall explanatory power, but in part it is also due to the increased collinearity that arises when $\Delta m_{t}$ and $\Delta g_{t}$ are replaced by constructed variables that are primarily linear combinations of lagged $\Delta m$ and $\Delta g$ values.

It therefore appears from this experiment that the effects stressed by Goldfeld and Blinder may indeed be of quantitative importance. Yet even in these estimates it remains the case that the coefficients of 
$\Delta m_{t}, \ldots, \Delta m_{t-4}$ sum to approximately 1.0 , whereas those on $\Delta g_{t}, \ldots, \Delta g_{t-4}$ sum to approximately zero. (The numbers are 1.08 and -0.14 , respectively. $)^{14}$

Once it is recognized-as seems necessary-that policy instruments are set in response to current or recent conditions, then the motivation for using high unemployment values of fiscal variables is lessened or eliminated. Furthermore, it even becomes unclear why a distinction is drawn between "discretionary" changes in expenditures or taxes and automatic changes brought about as a result of the built-in stabilizers. It would be appropriate to distinguish empirically between automatic and nonautomatic instrument changes if there were theoretical reasons to believe that these would have different effects on nominal GNP, but the econometric reasons apparently motivating Andersen and Jordan (1968) do not seem applicable. ${ }^{15}$ Consequently, it would appear that there remains room for an empirical study that emphasizes the endogenouspolicy effects emphasized by Goldfeld and Blinder, and that also considers the impact on aggregate demand of tax changes brought about by the built-in stabilizers of the U.S. tax system. A major reason why such a study is still lacking is the difficulty in modeling policy behavior, together with the absence of genuine exogenous variables.

\subsection{The Modigliani-Ando study}

Let us now turn to the rather interesting experiment conducted by Modigliani and Ando (1976), who hypothesize that (even ignoring endogenous-policy issues) estimates of policy multipliers obtained by means of the St. Louis approach are extremely unreliable. In support of that hypothesis, Modigliani and Ando report that the St. Louis equation, when estimated using artificial data generated by simulations of the MPS model, provides very poor estimates of that model's known multipliersestimates that are on the low side for fiscal multipliers and on the high side for monetary multipliers. Although this finding does not literally imply that the St. Louis estimates of the economy's multipliers are incorrect, it has been regarded by several reviewers ${ }^{16}$ as tending to discredit the St. Louis procedure and, thus, its results.

Reflection suggests, however, that this conclusion may not be warranted: The reason for doubt involves the point made above-that there are virtually no macroeconomic variables that can appropriately be treated as exogenous. If that point is correct, then the Modigliani-Ando experiment will be misleading in the following way. Under the hypothesis at handthat there are no exogenous variables-the MPS model (which treats a large number of variables as exogenous) incorrectly omits a large number of behavioral relationships analogous to (3). Therefore the "true" multi- 
plier values for the MPS model reported by Modigliani and Ando correspond to the $\beta(L)$ and $\gamma(L)$ values in Eq. (2). But estimates of the MPS multipliers obtained by the St. Louis approach correspond to the $\beta^{\prime}(L)$ and $\gamma^{\prime}(L)$ coefficients in (5), with $a_{j}$ values in (3) being whatever is implied by the historical values of the variables treated (incorrectly) as exogenous, the historical values of the policy instruments, and the simulated values of the model's endogenous variables. In other words, the comparison reported is between actual MPS values of the coefficients in (2) and estimated values of the coefficients in (5). Since these coefficients are truly different, under the hypothesis that there are no exogenous variables in reality, the discrepancy between estimated and true values does not indicate unreliability of the estimation procedure. ${ }^{17}$ This argument, it should be said, seems to amount to an elaboration of the comment provided by Darby (1976).

\subsection{Evidence from large models}

One useful feature of the Meyer-Rasche survey is its compact tabulation of policy multipliers for real GNP implied by seven prominent macroeconometric models. Although there is considerable disagreement among the other models concerning the magnitudes of fiscal and monetary multipliers, the St. Louis results do depart significantly from the average values of the other models. The government spending multiplier after four quarters, for example, is 0.5 for the St. Louis model as compared with a mean of 2.17 for the BEA, Brookings, Michigan, DRI, MPS, and Wharton models. In the case of the monetary variable, the comparison is not straightforward, because the St. Louis multipliers pertain to an M1 variable, and the others pertain to unborrowed reserves. But the othermodel average about four quarters is 3.0 , so the St. Louis value of 4.4 is much greater in elasticity terms, the ratio of M1 to unborrowed reserves being about 10 .

It will be noted that these multipliers are for real GNP, so their magnitudes depend upon the model's precise specifications of dynamic Phillips relationships. Since it is well known that there exist major disagreements over the proper specification of this relationship, it is, in principle, not surprising that the multipliers diverge. What one might hope for is some agreement concerning nominal GNP multipliers. That, in any event, is the topic under discussion in this paper-the relative impact of monetary and fiscal actions on aggregate demand.

But the foregoing statement applies only in principle. In fact, the predicted price level responses from any of the models in question are so slow that four-quarter multipliers are essentially the same both for nominal and real GNP. Thus we see that there is a considerable 
discrepancy between St. Louis and other-model responses to a monetary policy action, though less than in the case of a fiscal policy action.

Niehans (1978) and McNelis (1980) have suggested that the implications of non-St. Louis econometric models are actually much more "monetarist" than most observers have recognized. Their argument starts with the idea that the proper comparison of fiscal versus monetary policy effects requires that an unreversed $\$ 1$ billion/year increase in government spending should be compared with a continuing sequence of $\$ 1$ billion increases, one per year, in the high-powered money stock. And when this comparison is made, it is found that "for every model except BEA and Wharton III ... the peak of the money multipliers must be many times as high as the peak of the hypothetical fiscal multipliers, a typical ratio being perhaps $15: 1 \ldots$ The proposition that the quantity of money matters much more than the way it is created is evidently common to both" monetarist and nonmonetarist models (Niehans 1978, 253).

At first glance, this argument seems flawed. What is the point of comparing effects of changes in stock and flow variables? But then one realizes that it is entirely appropriate to compare an unreversed $\$ 1$ billion change in expenditures financed by bond sales with a similar expenditure change financed by money issues-the bond or money issues going on period after period with total tax receipts unchanged. And, clearly, the second of these sequences is equivalent to the first plus a continuing sequence of open-market bond purchases. Thus the bond-financed expenditure increase and the sequence of open-market purchases are the two constituent parts of a money-financed expenditure increase. If the second constituent is much larger than the first, as Niehans and McNelis claim, then their comparison would be both sensible and justified.

Continuing to reflect reminds one, however, that the simulation experiments actually carried out in the large-scale models are ones that hold constant tax rates, not tax receipts. Thus, putative bond-financed expenditures and bond-financed money stock expansions are in fact tax financed to a considerable extent. This would tend, since the models are not Ricardian, to depress multiplier values. It is not obvious to me that this tends to bias the results in favor of either type of policy action, but it would be preferable to compare the effects of the following two experiments:

(i) an unreversed expansion of government expenditures financed by bond sales, with unchanged tax-receipt and money-stock paths.

(ii) an unreversed expansion of government expenditures financed by (high-powered) money issue, with unchanged tax-receipt and bond-stock paths. 
I would not be surprised if the outcome of such an experiment were to support the Niehans-McNelis position-which in turn supports that of St. Louis to a considerable extent-but as far as I can tell it has not yet been conducted.

\subsection{Sims's VAR evidence}

Before concluding this section, we should mention the argument recently advanced by Sims $(1980,1982)$ to the effect that the impact of monetary policy actions on GNP is extremely small. This argument stems from vector autoregression (VAR) results, obtained by Sims, that show that money-stock innovations ${ }^{18}$ have very little explanatory power for U.S. postwar output when an interest rate is included among the VAR system's variables. These results have been interpreted as indicating that monetary policy actions have been an unimportant source of movements in real GNP-which would be, given the apparent slowness of price level responses, inconsistent with St. Louis-type results for nominal GNP as well. In a brief analytical note, however, I have shown that this conclusion is not implied by the empirical results in question (McCallum 1983). The point is that money-stock innovations do not necessarily reflect irregular components of monetary policy. Indeed, when the Fed uses an interest rate as its operating instrument-as it has during most of the postwar period-it is likely that its irregular actions will be better represented by a VAR system's interest rate innovations than by its money-stock innovations. ${ }^{19}$ And in fact interest-rate innovations do contribute importantly to output movements in Sims's results. Thus, it cannot be concluded that the actions of the monetary authority are unimportant for the explanation of output and nominal GNP movements. ${ }^{20}$

\section{Theoretical Issues}

Let us begin the theoretical discussion by reviewing the effects of monetary and fiscal actions on aggregate demand in a Ricardian economy-that is one in which agents take account of the government budget restraint (GBR) in making savings-consumption decisions for an effectively infinite planning horizon. ${ }^{21}$ Under such conditions the asset value of government bonds held by the public is offset by the present value of extra future taxes necessitated by the existence of these bonds, so the latter do not constitute wealth to the private sector as a whole. Thus a one-period tax reduction financed by bond sales has no effect on aggregate demand, for the implied increase in future taxes just offsets the effect on wealth of the 
reduction of current taxes. This Ricardian equivalence result, well known from the work of Barro $(1974,1984)$, provides the basis for a comparative analysis of monetary and fiscal policy effects.

The case of a tax reduction financed by money creation is quite different, for the asset value of the additional money is not offset by extra implied future taxes, of which there are none. ${ }^{22}$ The added nominal wealth may be negated in real terms by inflation, but the latter comes about as the result of an upward shift in aggregate demand, which is precisely the effect being claimed. Thus, the fact that inflation may, for some purposes, be viewed as imposing a "tax" does not alter the validity of the statement beginning this paragraph; a money-financed tax cut increases nominal wealth and aggregate demand.

Consequently, since a money-financed tax cut (of, say, $\$ \lambda$ ) and a bondfinanced tax increase (of $\$ \lambda$ ) are together equivalent to an open-market purchase, we see that an open-market purchase unambiguously increases aggregate demand (in a Ricardian economy). ${ }^{23}$ This result clearly implies that an increase in government spending must have a larger stimulative effect on aggregate demand if it is money financed rather than bond financed, for the difference in the two actions is precisely an open-market purchase (or sequence of purchases if we are discussing an unreversed increase in government purchases). ${ }^{24}$

It remains to be considered whether a bond- (or tax-) financed increase in government purchases will have a nonzero effect on aggregate demand. Effects of both temporary and permanent changes in government spending in a Ricardian world have been analyzed, in nonmathematical but careful fashion, by Barro $(1984,309-312$ and 316-320). In the case of a temporary increase there is an increase in output and in the real rate of interest. The latter translates, in the absence of inflation, into a rise in the nominal rate. For portfolio balance with a constant money stock, nominal income must then rise, if the income elasticity of real money demand is less than unity. To see this, let us write the money demand function as

$$
m-p=\alpha_{0}+\alpha_{1} y-\alpha_{2} r,
$$

where $m, p$, and $y$ are in logarithmic terms, $r$ is the interest rate, and all parameters are positive. This equation may be rearranged to read

$$
y+p=m-\alpha_{0}+\left(1-\alpha_{1}\right) y+\alpha_{2} r,
$$

so if $\alpha_{1}<1$ the increases in both $y$ and $r$ tend to increase $y+p$, the log of nominal income. In the case of a permanent increase in government spending, Barro's analysis leads to no chnage in $r$ but, again, to an increase in $y$, so again (7) indicates a rise in $y+p .^{25}$ Thus we see that an 
increase in (real) government spending tends to induce an increase in aggregate demand.

In summary, a Ricardian analysis suggests that (i) open-market purchases are expansionary, so (ii) money-financed spending increases or tax cuts are more expansionary than bond-financed ones. Indeed, (iii) bondfinanced tax cuts have no effect on aggregate demand, but (iv) bondfinanced spending increases are expansionary.

Now it is, of course, not the case that Ricardian assumptions are literally satisfied by the U.S. economy. But the Ricardian model may nevertheless provide a useful first approximation to the workings of the economy, a fruitful starting point for thinking about the effects of policy actions. In particular, it would seem more appropriate to regard bonds as contributing to private wealth not at all, than to regard them as doing so fully. If each dollar of bonds functions macroeconomically as $k$ dollars of net private wealth-which is the way Patinkin $(1965,289)$ puts it-then the value of $k$ is (I would conjecture) much closer to 0.0 than to $1.0{ }^{26}$

The relevance of this observation is, of course, that most of the theoretical literature of monetary versus fiscal policy effects has presumedusually without discussion -that bonds constitute wealth fully (i.e., that $k=1.0$ ). Indeed, this literature abounds with paradoxical results that obtain in large part because of wealth effects due to ongoing expansion or contraction of government debt. ${ }^{27}$ Another source of paradox in this literature-the exposition of which emphasizes the role of the $\mathrm{GBR}^{28}$-has been the practice of focusing on "long-run" effects, with the latter somewhat misleadingly defined so as to require a balanced budget. The inappropriateness of this terminology is emphasized by occasional statements concerning the comparative long-run effects of money- and bond-financed deficit spending. ${ }^{29}$

In any event there is one contention with which I want to take issue that appears in this literature: the notion that open-market purchases are contractionary or that, as Blinder and Solow $(1976,500)$ put it, "the longrun effect of government spending is greater when deficits are bondfinanced than when they are money-financed." 30 The basis of this contention is, as explained in McCallum $(1981,136)$, that in models of the type now under discussion either the contention is true or the economy is dynamically unstable when deficits are bond financed (i.e., when paths of spending, the money stock, and income tax rates are determined exogenously so that the stock of bonds must adjust to satisfy the GBR). Then by assuming stability, the authors in question obtain the result. But, as is argued in detail in McCallum (1981, 136-137), the appropriate conclusion is rather that the economy is unstable ${ }^{31}$ under these conditions, and open-market purchases are expansionary even according to the models and concepts in question. ${ }^{32}$ That conclusion is in no way refuted by the 
observed stability of the U.S. economy, because neither the money stock nor taxes are in fact managed in the way assumed by the setup in which the analysis is conducted.

\section{Conclusions}

The substantive conclusions of the foregoing investigation/review are fairly easy to discern and are not very dramatic. The clearest is that an open-market increase in the money stock has a stimulative effect on aggregate demand-a conclusion that, in turn, implies that a moneyfinanced increase in expenditures (or reduction in taxes) is more stimulative than a bond-financed increase. This conclusion is supported by empirical results obtained both from St. Louis-style estimates and from large-scale econometric models. Furthermore, the conclusion is also supported by theoretical analysis involving both Ricardian and non-Ricardian assumptions.

In the case of pure fiscal policy actions-that is, bond-financed tax cuts or bond-financed expenditure increases-the situation is not as clear. But theory suggests that the latter should be at least as stimulative as the former and most probably stimulative to a positive extent. The evidence on these points is mixed but is not obviously inconsistent with the theoretical predictions.

With respect to the textbook issue concerning the relative (per dollar) effect of pure monetary and fiscal actions, the evidence seems-in a rather disorderly way-to support the notion that a sequence of $\$ \lambda$ open-market purchases, on each period, will be considerably more stimulative than a single but unreversed $\$ \lambda /$ period, bond-financed increase in expenditures.

It might be added, however, that it is unclear that any great importance attaches to this last issue, at least from a policy perspective, provided that each type of policy has nonnegligible effects. If the object of the debate is to determine whether monetary or fiscal variables would serve better as instruments to be manipulated for stabilization purposes, then attention should be focused on the relative accuracy of the effects rather than on the per dollar magnitudes. Adjustments in the instrument settings do not themselves involve costs, in terms of destroyed resources, as is implicitly suggested by the view that it is relative magnitudes that matter. ${ }^{33}$ Nor is it entirely clear why, from a policy standpoint, ${ }^{34}$ so much attention has been devoted to whether the sum of fiscal policy coefficients is zero when individual coefficients are significantly nonzero. Only a minor quibble ${ }^{35}$ keeps me from sharing Fischer's (1976) view that "if fiscal policy had significant short-term effects . . . but no long-run effects it would be an ideal stabilization tool." 
More generally, the essential issues concerning stabilization policy that continue to divide macroeconomists are those concerned with, first, the desirability of activist policy and, second, whether activist policy (if desirable) should be executed according to well-specified rules or in a periodby-period discretionary manner. ${ }^{36,37}$ As various writers have noted, ${ }^{38}$ neither of these issues is strongly dependent upon the outcome of the relative magnitudes question. That does not imply, however, that the monetary versus fiscal policy debate has been unenlightening. On the contrary, the various ins and outs of the discussion have served valuably to enhance knowledge and awareness of the central importance of monetary actions as determinants of nominal income. That contribution is easy to belittle or overlook, given today's wide acceptance of that importance. But the formation of today's views-that is, the dramatic change away from the situation described by Cagan-amounted to a major overhaul in the practice of macro and monetary economics, and this change was aided substantially by the monetary versus fiscal policy debate.

\section{Notes}

1. Another interesting sign of the items is provided by Michael Parkin's first notable publication (Lipsey and Parkin 1970), which centers on a "prototype model" of the wage and price inflation process. The model's two endogenous variables are the money wage and the price level; its exogenous variables are import prices, output/manhour, the unemployment rate, and a measure of trade union aggressiveness. Unless I am mistaken, there is no mention of "money" in the entire paper. This example will be appreciated most by those of us who know and admire Parkin's later work as a monetary economist.

2. The original paper was Andersen and Jordan (1968), soon followed by Andersen and Carlson (1970). Other notable items in the series include Carlson (1978), Hafer (1982), and Batten and Thornton (1983).

3. Friedman and Meiselman used $M 2$ as their monetary variable and defined autonomous expenditures as "net private domestic investment plus the government deficit on income and product account plus the net foreign balance" (1963) 184). They also calculated partial correlations and devoted some attention to quarterly data.

4. An interesting predecessor of the Andersen-Jordan study, which probably influenced the latter, is Brunner and Balbach (1959).

5. Carlson (1978) indicates that the relative change specification passes, and the absolute change specification fails, tests for the absence of disturbance heteroskedasticity.

6. Or variables. My discussion proceeds as if only one such variable were omitted solely for convenience of exposition.

7. The impact of variables that follow smooth exponential trends is, of course, picked up by the constant term. This was noted (for linear trends) by Andersen and Jordan (1968).

8. That the disturbance in (5) is a complicated function of current and lagged values of the disturbance in (1) does not necessarily imply that the former is serially correlated, for the properties of the latter are unknown. 
9. This point was made by Andersen and Jordan (1968), Darby (1976), and probably others. It will arise again in the discussion of the Modigliani-Ando (1976) results.

10. It is a Keynesian multiplier model.

11. Meyer and Rasche $(1980,59)$ conclude their discussion of this measurement issue as follows: "However, the modifications... have not generally resulted in dramatic changes in sample reduced-form equations."

12. Potential empirical importance is suggested by Modigliani and Ando $(1976,40-41)$.

13. Whether the magnitudes of these sums are important will be discussed in Section 4.

14. Similar conclusions obtain when once- and twice-lagged values of the unemployment rate for adult males are also used in the first-stage regressions, although in this case the results are closer to those obtained by OLS.

15. For a recent review of the theory of automatic stabilizers, see Christiano (1984).

16. These include Meyer and Rasche (1980, 62), Purvis (1980, 108-9), and McCallum (1978, 322).

17. Variants of this argument would appear to apply to the other ModiglianiAndo results.

18. A variable's innovation is its one-period ahead prediction error when the prediction is the orthogonal projection of the variable on all past values of the variables included in the system under consideration.

19. I do not mean to claim that interest-rate innovations actually reflect only policy surprises. They do in the formal model in McCallum (1983) but would not if the Fed's operating procedure were slightly different than that assumed. The main point of the demonstration is that it is unreasonable to use money-stock innovations as representative of monetary policy surprises.

20. This argument does not imply that interest rates are, in general, better "indicators" than money-stock growth rates of monetary policy impulses; the relations mentioned in the text hold only for innovations.

21. Also needed, of course, is the assumption that taxes are lump sum in nature-that is, have no major substitution effects. That finite-lived individuals may have effectively infinite planning horizons was shown by Barro (1974).

22. See Patinkin $(1965,289)$. The reason money is willingly held despite the absence of the interest payments is, of course, that it provides transactionfacilitating services to its holders.

23. An open-market purchase leaves fewer bonds outstanding and so requires smaller interest payments in the future by the government. Under Ricardian assumptions it does not matter whether this reduction in payments is accompanied by lower taxes or by bond growth.

24. That maintained deficits are possible under bond finance, as well as under money finance, is demonstrated in McCallum (1984a).

25. This type of result can be shown to hold in the Sidrauski-type version of the Ricardian model used by McCallum (1984a) as follows. As in Barro (1984), let the consumer obtain utility from government-provided services and express this by writing the within-period utility function for the representative household as $u\left(c_{t}+\alpha g_{t}, m_{t}\right)$ with $0<\alpha<1$. The budget constraint is not changed, so the household's optimality conditions remain (3)-(10) in McCallum (1984a, 128129). Consider alternative steady states with zero inflation. Combining (4) and (5) then yields 


$$
\beta u_{2}(c+\alpha g, m)=(1-\beta) u_{1}(c+\alpha g, m) .
$$

In this particular model an increase in $g$ has no effect on the steady-state value of $k$ (see p. 129), so $c+g$ is unaffected, and an increase in $g$ lowers $z \equiv c+\alpha g$. From the equation above we have

$$
\frac{d m}{d z}=\frac{u_{21}+\beta^{-1}(\beta-1) u_{11}}{u_{12}(1-\beta) \beta^{-1}-u_{22}} .
$$

From the latter plus the conditions $u_{11}<0, u_{22}<0$, and $u_{12}>0$, we find that $d m / d z>0$. So real money balances fall with a reduction in $z$ coming from an increase in $g$. But with a constant money stock, that implies an increase in the price level and thus in aggregate demand.

26. This condition does not require that individuals' planning horizons extend beyond their own lifetimes. I would also conjecture that analysis using the recently developed approach of Blanchard (1984) would support my main conclusions.

27. Some of the prominent items are included in volumes edited by Gordon (1974) and Stein (1976). Also influential were Christ (1968), Brunner and Meltzer (1972), and a series of papers by Blinder and Solow (1973, 1974, 1976). A recent review, which shares the criticized presumption of the items reviewed, is Mayer (1984).

28. It is worth noting that analysis that ignores the GBR is not thereby discredited, as long as it does not pretend that time paths of money, bonds, spending, and taxes can all be specified arbitrarily. An analysis that specifies paths for only three of these variables arbitrarily and ignores the fourth, may be perfectly logical as long as it does not require an infeasible path for the fourth variable-for example, a path along which the bond stock grows exponentially at a rate exceeding the growth rate of output by more than the rate of time preference (McCallum 1984a). Failing to keep track of the fourth variable may lead to errors if the model is non-Ricardian, because of induced shifts in behavioral relations. But if it is Ricardian and the fourth variable is bonds or tax receipts, then such shifts will not occur.

29. See, for example, Blinder and Solow $(1976,506)$.

30. Their contention is accepted by Mayer (1984).

31. In McCallum (1981) it is suggested that the dynamic instability in question can be avoided if the rate of output growth exceeds the after-tax real rate of return. But with an income tax, a maximizing analysis in a Ricardian model of the type used in McCallum (1984a) indicates that the steady-state, after-tax real rate of return will equal the rate of growth plus the rate of time preference. So the condition mentioned in my earlier paper as an escape from instability cannot hold in the vicinity of the steady state. I was thus wrong to quarrel, in my 1981 paper, with the first of the two "messages" suggested by Blinder and Solow (1976).

32. This conclusion seems to agree with that of Christ $(1979,533)$.

33. A similar point was mentioned by Meltzer $(1969,31)$ but only with respect to monetary instruments. Robert King has suggested to me that there may be resource costs associated with adjustments of tax schedules or government expenditures, that would tend to make money the better instrument.

34. The question of whether the cumulative effect of such actions is stimulative, contractionary, or neither may be of theoretical interest, since it bears on the appropriateness of competing theories. It is not the case, however, that a value of unity for the sum of the monetary policy coefficients is necessary for "long run" 
monetary neutrality. For a recent discussion relating to that point, see McCallum (1984b).

35. The quibble is that zero effects after the first period, rather than zero long-run effects, would appear to be preferable.

36. The efficacy of various possible instruments and institutional arrangements is also of importance.

37. The advantage of rule-like behavior of monetary policy has been articulated by Barro and Gordon (1983).

38. Among these are Sargent (1976), Modigliani (1977), and McCallum (1978).

\section{References}

Ackley, Gardner. 1961. Macroeconomic Theory. New York: Macmillan.

Andersen, Leonall C., and Jerry L. Jordan. 1968. Monetary and fiscal actions: A test of their relative importance in economic stabilization. Federal Reserve Bank of St. Louis Review 50: 11-24.

Andersen, Leonall C., and Keith M. Carlson. 1970. A monetarist model for economic stabilization. Federal Reserve Bank of St. Louis Review 52: 7-25.

Ando, Albert, and Franco Modigliani. 1965. The relative stability of monetary velocity and the investment multiplier. American Economic Review 50: 693-728.

Barro, Robert J. 1974. Are government bonds net wealth? Journal of Political Economy 82: 1095-1117. 1984. Macroeconomics. New York: Wiley.

Barro, Robert J., and David B. Gordon. 1983. A positive theory of monetary policy in a natural rate model. Journal of Political Economy 91: 589-610.

Batten, Dallas S., and Daniel L. Thornton. 1983. Polynomial distributed lags and the St. Louis equation. Federal Reserve Bank of St. Louis Review 65: 13-25.

Blanchard, Olivier J. 1984. Debt, deficits, and finite horizons. NBER Working Paper No. 1389.

Blinder, Alan S., and Robert M. Solow. 1973. Does fiscal policy still matter? Journal of Public Economics 2: 319-37.

1974. Analytical foundations of fiscal policy. In The Economics of Public Finance. Washington: Brookings Institution.

1976. Does fiscal policy still matter? A reply. Journal of Monetary Econom ics 2: 501-10.

Brunner, Karl, and Anatol B. Balbach. 1959. An evaluation of two types of monetary theories. In Proceedings of the 34th Annual Conference of the Western Economic Association.

Brunner, Karl, and Allan H. Meltzer. 1972. Money, debt, and economic activity. Journal of Political Economy 80: 951-77.

Cagan, Phillip. 1978. Monetarism in historical perspective. In The Structure of Monetarism, ed. T. Mayer. New York: Norton.

Carlson, Keith M. 1978. Does the St. Louis equation now believe in fiscal policy? Federal Bank of St. Louis Review 60: 13-19

Christ, Carl F. 1968. A simple macroeconomic model with a government budget restraint. Journal of Political Economy 76: 53-67.

1979. On fiscal and monetary policies and the government budget restraint. American Economic Review 69: 526-38.

Christiano, Lawrence J. 1984. A reexamination of the theory of automatic stabilizers. In Carnegie-Rochester Conference Series on Public Policy, Vol. 20, 147-206. 
Corrigan, E. Gerald. 1970. The Measurement and importance of fiscal policy changes. Federal Reserve Bank of New York Monthly Review 52: 133-45.

Darby, Michael. 1976. Comments. In Monetarism, ed. J. L. Stein. Amsterdam: North-Holland.

De Prano, Michael, and Thomas Mayer. 1965. Tests of the relative importance of autonomous expenditures and money. America Economic Review 55: 729-52.

Fischer, Stanley. 1976. Comments. In Monetarism, ed. J. L. Stein. Amsterdam: North-Holland.

Friedman, Benjamin M. 1977. Even the St. Louis model now believes in fiscal policy. Journal of Money, Credit, and Banking 9: 365-67.

1984. Money, credit, and interest rates in the business cycle. NBER Working Paper No. 1482.

Friedman, Milton, and David Meiselman. 1963. The relative stability of monetary velocity and the investment multiplier in the United States, 1897-1958. In Stabilization Policies. Englewood Cliffs: Prentice-Hall.

Goldfeld, Stephen M., and Alan S. Blinder. 1972. Some implications of endogenous stabilization policy. Brookings Papers on Economic Activity No. 3: $585-640$.

Gordon, Robert A., and Lawrence Klein, eds. 1965. Readings in Business Cycles. Homewood, Il.: Richard D. Irwin.

Gordon, Robert J., ed. 1974. Milton Friedman's Monetary Framework. Chicago: University of Chicago Press.

Gordon, Robert J., and Stephen King. 1982. The output costs of disinflation in traditional and vector autoregression models. Brookings Papers on Economic Activity No. 1: 205-42.

Hafer, R. W. 1982. The role of fiscal policy in the St. Louis equation. Federal Reserve Bank of St. Louis Review 59: 17-22.

Hester, Donald D. 1964. Keynes and the quantity theory: A comment on the Friedman-Meiselman CMC paper. Review of Economics and Statistics 46: 364 77.

Lipsey, Richard G., and J. M. Parkin. 1970. Incomes policy: A reappraisal. Economica 37: 115-38.

Litterman, Robert. 1982. Specifying vector autoregressions for macroeconomic forecasting. Working Paper No. 208, Federal Reserve Bank of Minneapolis.

Lucas, Robert E., Jr. 1976. Econometric policy evaluation: A critique. In Carnegie-Rochester Conference Series in Public Policy, Vol. 1, K. Brunner and A. H. Meltzer, eds. Amsterdam: North-Holland.

Mayer, Thomas. 1984. The government budget constraint and standard macrotheory. Journal of Monetary Economics 13: 371-79.

McCallum, Bennett T. 1981. Monetarist principles and the money stock growth rule. American Economic Review 71: 134-38.

1983. A reconsideration of Sims's evidence concerning monetarism. Economics Letters 13: 167-71.

1984a. Are bond-financed deficits inflationary? A Ricardian Analysis. Journal of Political Economy 92: 123-35.

1984b. On low-frequency estimates of long-run relationships in macroeconomics. Journal of Monetary Economics 14: 3-14.

1978. Book review. Journal of Monetary Economics 4: 321-24.

McNelis, Paul D. 1980. Irrepressible monetarists conclusions from a nonmonetarist model. Journal of Monetary Economics 6: 121-27.

Meltzer, Allan H. 1969. Money, intermediation, and growth. Journal of Economic Literature 7: 27-57. 
Meyer, Lawrence H., and Robert H. Rasche. 1980. Empirical evidence on the effects of stabilization policy. In Stabilization Policies: Lessons from the '70s and Implications for the '80s. Center for the Study of American Business.

Modigliani, Franco. 1977. Monetarist controversy or, should we forsake stabilization policies? American Economic Review 67: 1-19.

Modigliani, Franco, and Albert Ando. 1976. Impacts of fiscal actions on aggregate income and the monetarist controversy: Theory and evidence. In Monetarism, ed. J. L. Stein. Amsterdam: North-Holland.

Neihans, Jurg. 1978. The Theory of Money. Balitmore: Johns Hopkins Press.

Patinkin, Don. 1965. Money, Interest, and Prices. 2d ed. New York: Harper and Row.

Purvis, Douglas D. 1980. Monetarism: A review. Canadian Journal of Economics 13: 96-122.

Sargent, Thomas J. 1976. A classical macroeconometric model for the United States. Journal of Political Economy 84: 207-38.

Sims, Christopher A. 1980. Comparison of interwar and postwar business cycles: Monetarism reconsidererd. American Economic Review 70: 250-57.

1982. Policy analysis with econometric models. Brookings Papers on Economic Activity No. 1: 107-52.

Stein, Jerome L., ed. Monetarism. Amsterdam: North-Holland.

Webb, Roy H. 1984. Vector autoregressions as a tool for forecast evaluation. Federal Reserve Bank of Richmond Economic Review 70: 3-11. 